\title{
Interceptive Treatment
}

National Cancer Institute

\section{Source}

National Cancer Institute. Interceptive Treatment. NCI Thesaurus. Code C82081.

Orthodontic treatment designed to take advantage of the active growth stage of a child's development in order to intercept orthodontic problems early and reduce or eliminate them. 